\title{
Diffusion-Weighted Imaging and Diffusion Tensor Imaging for Differentiating High-Grade Glioma from Solitary Brain Metastasis: A Systematic Review and Meta-Analysis
}

\author{
(D)C.H. Suh, (D)H.S. Kim, (D)S.C. Jung, and DS.J. Kim
}

O- $\equiv$

\begin{abstract}
BACKGROUND: Accurate diagnosis of high-grade glioma and solitary brain metastasis is clinically important because it affects the patient's outcome and alters patient management.
\end{abstract}

PURPOSE: To evaluate the diagnostic performance of DWI and DTI for differentiating high-grade glioma from solitary brain metastasis.

DATA SOURCES: A literature search of Ovid MEDLINE and EMBASE was conducted up to November 10, 2017.

STUDY SELECTION: Studies evaluating the diagnostic performance of DWI and DTI for differentiating high-grade glioma from solitary brain metastasis were selected.

DATA ANALYSIS: Summary sensitivity and specificity were established by hierarchic logistic regression modeling. Multiple subgroup analyses were also performed.

DATA SYNTHESIS: Fourteen studies with 1143 patients were included. The individual sensitivities and specificities of the 14 included studies showed a wide variation, ranging from $46.2 \%$ to $96.0 \%$ for sensitivity and $40.0 \%$ to $100.0 \%$ for specificity. The pooled sensitivity of both DWI and DTI was $79.8 \%$ (95\% Cl, 70.9\%-86.4\%), and the pooled specificity was $80.9 \%(95 \% \mathrm{Cl}, 75.1 \%-85.5 \%)$. The area under the hierarchical summary receiver operating characteristic curve was $0.87(95 \% \mathrm{Cl}, 0.84-0.89)$. The multiple subgroup analyses also demonstrated similar diagnostic performances (sensitivities of $76.8 \%-84.7 \%$ and specificities of $79.7 \%-84.0 \%$ ). There was some level of heterogeneity across the included studies $\left(1^{2}=36 \%\right)$; however, it did not reach a level of concern.

LIMITATIONS: The included studies used various DWI and DTI parameters.

CONCLUSIONS: DWI and DTI demonstrated a moderate diagnostic performance for differentiation of high-grade glioma from solitary brain metastasis.

ABBREVIATIONS: $\mathrm{FA}=$ fractional anisotropy; HSROC = hierarchic summary receiver operating characteristic; $\mathrm{MD}=$ mean diffusivity; PRISMA $=$ Preferred Reporting Items for Systematic Reviews and Meta-Analyses; QUADAS-2 = Quality Assessment of Diagnostic Accuracy Studies-2

$\mathrm{T}$ he accurate diagnosis of high-grade glioma and solitary brain metastasis is clinically important because it affects the patient's outcome and alters patient management. ${ }^{1,2}$ Because

Received December 15, 2017; accepted after revision March 7, 2018

From the Department of Radiology and Research Institute of Radiology, University of Ulsan College of Medicine, Asan Medical Center, Seoul, Republic of Korea.

This study was supported by a grant from the National R\&D Program for Cancer Control, Ministry of Health and Welfare, Republic of Korea (1720030).

Please address correspondence to Ho Sung Kim, MD, PhD, Department of Radiology and Research Institute of Radiology, University of Ulsan College of Medicine, Asan Medical Center, 86 Asanbyeongwon-Gil, Songpa-Gu, Seoul 138-736, Republic of Korea; e-mail: radhskim@gmail.com

-- Indicates open access to non-subscribers at www.ajnr.org

$\equiv$ Indicates article with supplemental on-line tables.

Indicates article with supplemental on-line photos.

http://dx.doi.org/10.3174/ajnr.A5650 high-grade glioma and solitary brain metastasis have similar findings on conventional MR imaging, the clinical context or patient history could be helpful. In addition, advanced MR imaging techniques have been introduced to assist in their differentiation.

Multiple studies report on the use of DWI and DTI for differentiating high-grade glioma from solitary brain metastasis. ${ }^{3-16}$ High-grade glioma typically shows an infiltrative growth pattern with invasion of the surrounding brain tissues, whereas brain metastasis shows an expansive growth pattern causing displacement of the surrounding brain tissue. ${ }^{17,18}$ In addition, high-grade glioma cells tend to produce large amounts of extracellular matrix, which play an important role in tumor growth and infiltration. ${ }^{19,20}$ Therefore, assessment of the enhancing tumor and perienhancing area with DWI and DTI parameters has been intro- 
duced. However, the results have been quite varied, and the utility of these techniques is still an issue under debate. ${ }^{7,9,12}$ Some studies have reported a high diagnostic performance for DWI or DTI; however, other studies have reported a low diagnostic performance or no added value of DWI or DTI compared with conventional MR imaging.

Therefore, we considered it appropriate to assess the diagnostic performance of DWI and DTI for differentiating high-grade glioma from solitary brain metastasis using the currently available published resources. We thus performed a systematic review and meta-analysis evaluating the diagnostic performance of DWI and DTI for differentiating high-grade glioma from solitary brain metastasis.

\section{MATERIALS AND METHODS}

The current systematic review and meta-analysis are reported according to the Preferred Reporting Items for Systematic Reviews and Meta-Analyses (PRISMA) guidelines. ${ }^{21}$ The following research question was established ${ }^{21}$ : What are the diagnostic performances of DWI and DTI for differentiating high-grade glioma from solitary brain metastasis?

\section{Literature Search}

A literature search of Ovid MEDLINE and EMBASE was conducted to find relevant original articles up to November 10, 2017. The search query combined equivalents for "glioma," "brain metastasis," "DWI," and "DTI" as follows: ((brain metastasis) OR (brain metastases) OR (metastatic brain tumor*) OR (intraaxial metastatic tumor ${ }^{\star}$ ) OR (cerebral metastasis) OR (cerebral metastases) OR (solitary metasta $\left.{ }^{\star}\right)$ AND ((glioblastoma) OR (glioma)) AND ((diffusion-weighted imaging) OR (diffusion-weighted imaging) OR (DWI) OR ("apparent diffusion coefficient") OR (diffusion tensor imaging) OR (DTI)). The literature search was restricted to English language publications. Any additional relevant articles identified were also investigated.

\section{Literature Selection}

Inclusion Criteria. We used the following inclusion criteria: 1) population: patients with a solitary enhancing brain lesion; 2) index test: DWI and DTI scans available; 3) reference standard: histopathologic diagnosis; 4) outcomes: differentiation of highgrade glioma (glioblastoma and/or anaplastic astrocytoma) from solitary brain metastasis, with sufficient data provided to establish $2 \times 2$ tables for sensitivity and specificity; and 5) articles published as original articles.

Exclusion Criteria. We applied the following exclusion criteria: 1) case reports/series (a sample size of $<10$ patients), conference abstracts, reviews, and notes; 2) studies including patients with low-grade gliomas; 3 ) studies including patients with recurrent brain metastasis; 4) insufficient information for reconstruction of $2 \times 2$ tables; and 5) a partially overlapping patient population. In the case of an overlapping study population, the study with the largest study population was selected. When $2 \times 2$ tables could not be established, authors of the eligible studies were contacted for further data.

\section{Data Extraction and Quality Assessment}

The following data were extracted from the included studies: 1) study characteristics: authors, year of publication, institution, duration of patient recruitment, study design (prospective versus retrospective), study enrollment (consecutive versus nonconsecutive), and reference standard; 2) patient characteristics: number of patients, number of patients with high-grade glioma, mean age, age range, and male/female ratio; 3 ) MR imaging characteristics: magnet field strength, scanner vendor, scanner model, channels of head coil, and MR imaging techniques including DWI, DTI, b-value $\left(\mathrm{s} \mathrm{mm}^{-2}\right)$, ROI placement, parameters, and cutoff values; and 4) MR imaging interpretation: number of readers, experience of readers, and blinding of readers to the reference standard.

The study quality was assessed using the Quality Assessment of Diagnostic Accuracy Studies-2 (QUADAS-2) tool. ${ }^{22}$ The literature search, literature selection, data extraction, and quality assessment were performed independently by 2 reviewers (C.H.S. and H.S.K.).

\section{Data Synthesis and Statistical Analysis}

The primary aim of this study was to determine the diagnostic performance of DWI and DTI for differentiating high-grade glioma from solitary brain metastasis. We obtained $2 \times 2$ tables from the studies to identify their individual sensitivities and specificities. Summary sensitivity and specificity were established by hierarchic logistic regression modeling (bivariate random-effects model and hierarchic summary receiver operating characteristic [HSROC] model). ${ }^{23-25}$ An HSROC curve with 95\% confidence and prediction regions was obtained, and the area under the HSROC curve was also calculated. Publication bias was investigated using the Deeks asymmetry test. ${ }^{26}$

Heterogeneity across the studies was evaluated as follows: 1 ) Cochran $\mathrm{Q}$ test $(P<.05$ indicating the presence of heterogeneity); 2) Higgins inconsistency index $\left(\mathrm{I}^{2} \text { test }\right)^{27}\left(\mathrm{I}^{2}=0 \%-40 \%\right.$, heterogeneity might not be important; $30 \%-60 \%$, moderate heterogeneity may be present; 50\%-90\%, substantial heterogeneity may be present; and 75\%-100\%, considerable heterogeneity); 3) visual assessment of a coupled forest plot or a Spearman correlation coefficient $(>0.6$ indicating a threshold effect) to assess a threshold effect (positive correlation between sensitivity and the falsepositive rate $)^{28}$; and 4) visual assessment of the difference in the 95\% confidence and prediction regions in the HSROC.

Multiple subgroup analyses were performed as follows: 1) studies using DWI, 2) studies using DTI, 3) studies including glioblastoma only, 4) studies including both glioblastoma and anaplastic astrocytoma, 5) studies using enhancing tumor for ROI placement, 6) studies using perienhancing area for ROI placement, 7) studies using fractional anisotropy (FA), 8) studies using mean diffusivity (MD), and 9) studies using perienhancing ADC or MD. Statistical analyses for the meta-analysis were performed by one of the reviewers (C.H.S., with 4 years of experience in performing systematic reviews and meta-analyses), using the metandi and midas modules in STATA 15.0 (StataCorp, College Station, Texas) and the mada package in R statistical and computing software, Version 3.4.1 (http://www.r-project.org/). $P<.05$ indicated statistical significance. 


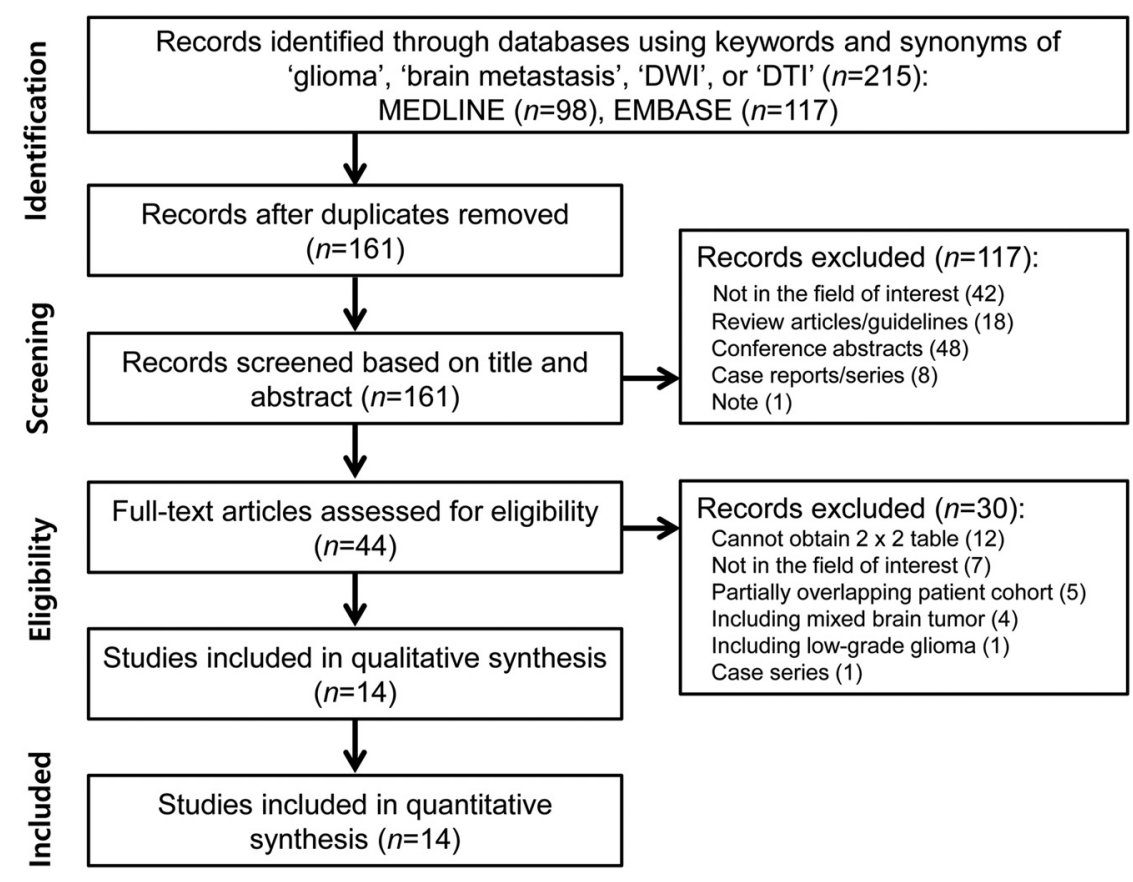

FIG 1. Flow diagram illustrating the study-selection process for the systematic review and meta-analysis.

\section{Quality Assessment}

The results of the quality assessment are illustrated in On-line Fig 1. In the patient-selection domain, 10 studies revealed an unclear risk of bias because of nonconsecutive enrollment. ${ }^{3,5-7,9,11-15}$ In the index test domain, 6 studies revealed an unclear risk of bias because it was unclear whether imaging analysis had been conducted blinded to the reference standard. ${ }^{3,5,7,9,15,16}$ In the reference standard domain, 2 studies revealed a high risk of bias, with 1 study not mentioning the reference standard ${ }^{6}$ and 1 study using both histopathology and clinical diagnosis. ${ }^{14}$ In the flow and timing domain, 13 studies revealed an unclear risk of bias because the time intervals between MR imaging and the reference standard were not mentioned. ${ }^{3,4,6-16}$ However, there were no concerns regarding the applicability of all 3 domains.

\section{RESULTS}

\section{Literature Search}

The detailed literature-selection process is illustrated in Fig 1. The literature search identified 215 articles. After we removed 54 duplicate articles, screening of the titles and abstracts of the remaining 161 articles yielded 44 potentially eligible articles. Full-text reviews were performed, and 30 studies were excluded because of the following: 1) twelve studies because the $2 \times 2$ table could not be obtained ${ }^{29-40} ; 2$ ) seven studies not in the field of interest ${ }^{41-47}$; 3) five studies with a partially overlapping patient cohort ${ }^{48-52}$; 4) four studies with mixed brain tumors ${ }^{53-56} ; 5$ ) one study with a low-grade glioma ${ }^{57}$; and 6) one case series. ${ }^{58}$ Fourteen studies evaluating the diagnostic performance of DWI and DTI for differentiating high-grade glioma from solitary brain metastasis, ${ }^{3-16}$ covering 1143 patients, were included in the analyses.

\section{Characteristics of the Included Studies}

The detailed study and patient characteristics are shown in On-line Table 1. Nine studies enrolled patients with glioblastoma only, ${ }^{3-7,10-12,15}$ while 5 studies enrolled patients with high-grade gliomas. ${ }^{8,9,13,14,16}$ Twelve studies used histopathology as the reference standard, ${ }^{3-5,7-13,15,16}$ and 1 study used histopathology and clinical diagnosis only for brain metastasis. ${ }^{14}$

The detailed MR imaging characteristics are described in On-line Table 2. DWI was used in 7 studies ${ }^{6,8,10-13,16}$; and DTI, in 7 studies. $^{3-5,7,9,14,15}$ A quantitative ADC value was used in 7 studies using DWI. ${ }^{6,8,10-13,16}$ Five of the 7 DTI studies used both FA and MD, ${ }^{3,5,9,14,15}$ whereas 2 studies used FA only. ${ }^{4,7}$ In terms of ROI placement, both enhancing tumor and perien-

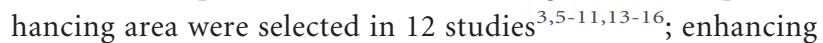
tumor only, in 1 study $^{4}$; and perienhancing area only, in 1 study. $^{12}$

\section{Diagnostic Accuracy}

The individual sensitivities and specificities of the 14 included studies showed a wide variation, ranging from $46.2 \%$ to $96.0 \%$ for sensitivity and $40.0 \%$ to $100.0 \%$ for specificity. The pooled sensitivity was $79.8 \%(95 \% \mathrm{CI}, 70.9 \%-86.4 \%)$, and the pooled specificity was $80.9 \%$ (95\% CI, 75.1\%-85.5\%) (Fig 2 and On-line Table 3). The area under the HSROC curve was 0.87 (95\% CI, 0.84-0.89; On-line Fig 2). The Deeks funnel plot demonstrated that no publication bias was present $(P=.98$; On-line Fig 3$)$.

In the investigation of heterogeneity, a Cochran $Q$ test showed that heterogeneity was not present $(\mathrm{Q}=3.117, d f=2, P=.104)$, and there was some level of heterogeneity across the included studies $\left(\mathrm{I}^{2}=36 \%\right)$; however, it did not reach a level of concern. Visual assessment of the coupled forest plots revealed no threshold effect (Fig 2), and the Spearman correlation coefficient was 0.188 (95\% CI, $-0.653-0.381$ ), also indicating no threshold effect. The HSROC curve illustrated a small difference between the $95 \%$ confidence prediction regions, indicating a low possibility of heterogeneity (On-line Fig 2).

\section{Multiple Subgroup Analyses}

On-line Table 4 shows the results of multiple subgroup analyses. In the subgroup analysis according to MR imaging technique, those studies using DWI showed a pooled sensitivity of $81.4 \%$ (95\% CI, 70.6\%-88.9\%) and a pooled specificity of $81.8 \%(95 \%$ CI, $69.5 \%-89.9 \%) .{ }^{6,8,10-13,16}$ Studies using DTI showed a pooled sensitivity of $77.0 \%(95 \% \mathrm{CI}, 62.3 \%-87.1 \%)$ and a pooled specificity of $80.3 \%$ (95\% CI, 73.5\%-85.7\%)..$^{3-5,7,9,14,15}$ There was no statistical difference between DWI and DTI $(P=.59)$. In the subgroup analysis according to study population, the studies including glioblastoma showed only a pooled sensitivity of $82.2 \%$ (95\% CI, $71.9 \%-89.3 \%)$ and a pooled specificity of $81.4 \%$ (95\% CI, 


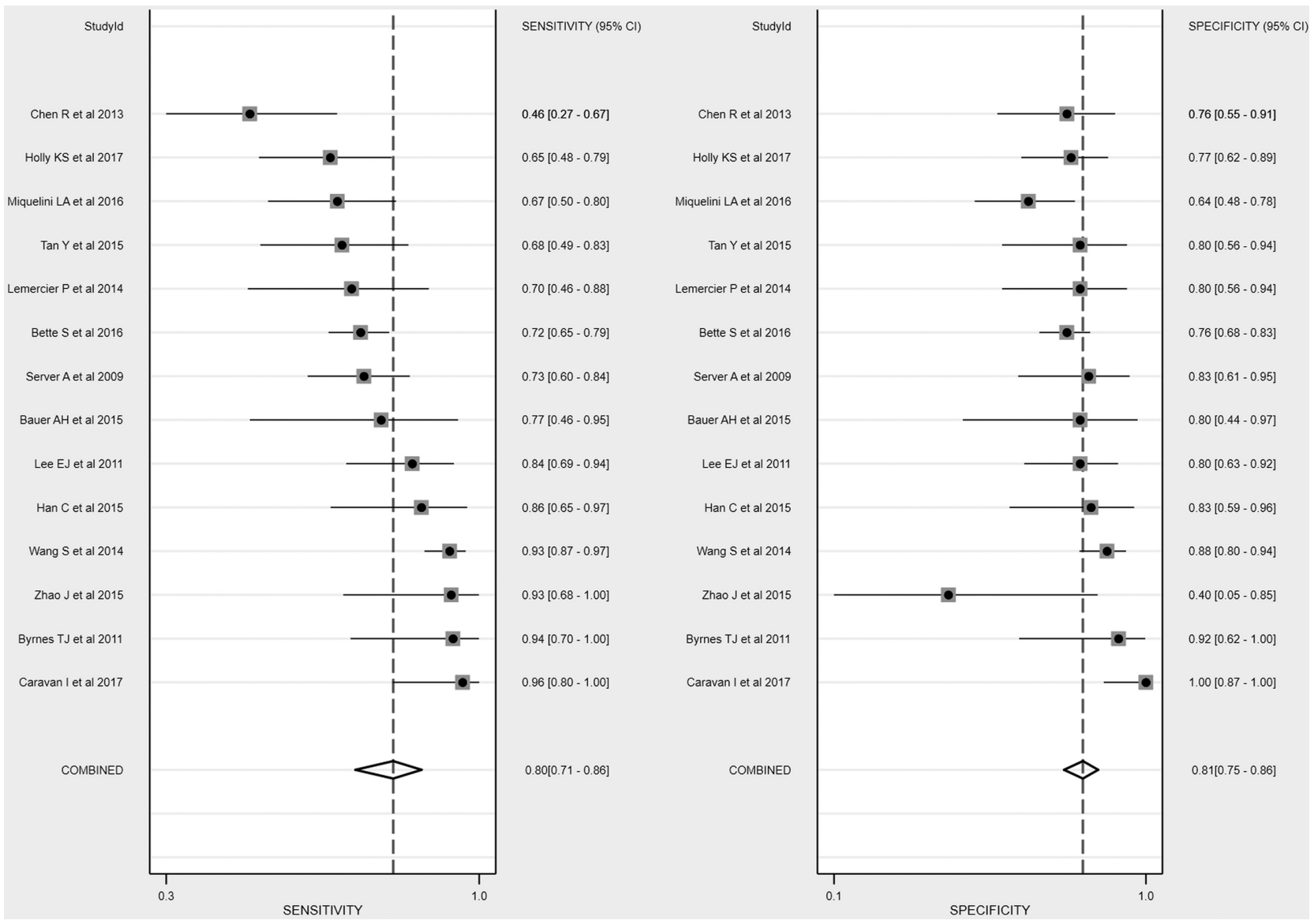

FIG 2. Coupled forest plots of pooled sensitivity and specificity. Numbers are pooled estimates with $95 \%$ confidence intervals in parentheses.

$74.8 \%-86.6 \%) .{ }^{3-5,13-16}$ Studies including both glioblastoma and anaplastic astrocytoma showed a pooled sensitivity of $76.8 \%(95 \% \mathrm{CI}, 61.45 \%-87.4 \%)$ and a pooled specificity of $81.2 \%\left(95 \%\right.$ CI, 69.9\%-88.9\%). ${ }^{6-12}$

In the subgroup analysis according to the ROI placement, studies using enhancing tumor showed a pooled sensitivity of $72.6 \%(95 \% \mathrm{CI}, 63.4 \%-80.3 \%)$ and a pooled specificity of $77.0 \%$ (95\% CI, 71.7\%-81.6\%). . $^{3,4,11,13,15}$ Studies using a perienhancing area showed a pooled sensitivity of $80.1 \%(95 \%$ CI, $69.1 \%-87.9 \%)$ and a pooled specificity of $81.0 \%$ (95\% CI, $70.6 \%-88.3 \%) .^{3,6,8-10,12,14,16}$ In the subgroup analysis according to DTI parameters, studies using FA showed a pooled sensitivity of $70.8 \%(95 \% \mathrm{CI}, 61.0 \%-79.0 \%)$ and a pooled specificity of $74.5 \%$ (95\% CI, 69.0\%-79.3\%)..$^{3,4,7,9,14,15} \mathrm{MD}$ showed a pooled sensitivity of $84.5 \%(95 \% \mathrm{CI}, 71.7 \%-92.1 \%)$ and a pooled specificity of $81.3 \%$ (95\% CI, 72.0\%-88.1\%). Studies using perienhancing ADC or MD showed a pooled sensitivity of $84.7 \%(95 \% \mathrm{CI}, 73.6 \%-91.6 \%)$ and a pooled specificity of $84.0 \%$ (95\% CI, 71.8\%-91.6\%). . $^{3,6,8,10,14,16}$

\section{DISCUSSION}

We identified 14 studies providing the diagnostic performance of DWI and DTI for differentiating high-grade glioma from solitary brain metastasis. DWI and DTI showed not only a wide range of individual sensitivities and specificities but also only a moderate diagnostic performance (ie, a pooled sensitivity of 79.8\% [95\% CI, 70.9\%-86.4\%] and a pooled specificity of $80.9 \%$ [95\% CI,
$75.1 \%-85.5 \%]$ ). Multiple subgroup analyses also demonstrated similar diagnostic performances (sensitivities of $76.8 \%-84.7 \%$ and specificities of $79.7 \%-84.0 \%$ ). DWI and DTI are rarely used as a single sequence, whereas DWI and DTI are usually part of a multiparametric MR imaging protocol for differentiating highgrade glioma from solitary brain metastasis. Therefore, DWI and DTI could actually be helpful in the context of multiparametric MR imaging.

High-grade glioma typically shows an infiltrative growth pattern with invasion of the surrounding brain tissues. However, brain metastasis shows an expansive growth pattern and displaces the surrounding brain tissue. ${ }^{10}$ Therefore, many researchers have used various advanced MR imaging techniques in attempts to differentiate the infiltrative edema of glioma from metastatic vasogenic edema. DWI and DTI have been used for testing the perienhancing area of solitary enhancing brain lesions; however, the results are conflicting. Two studies reported that the mean minimum perienhancing ADC values in high-grade glioma were significantly higher than those in brain metastases, ${ }^{6,8}$ whereas 1 study reported lower mean minimum perienhancing ADC values in high-grade glioma. ${ }^{10}$ Two studies also reported that perienhancing MD was significantly lower in high-grade glioma than in brain metastasis. ${ }^{3,14}$

The current meta-analysis revealed a moderate diagnostic performance in 6 studies that used perienhancing ADC or MD as a parameter to determine optimal cutoff values, with a pooled sen- 
sitivity of $84.7 \%$ (95\% CI, 73.6\%-91.6\%) and a pooled specificity of $84.0 \%$ (95\% CI, 71.8\%-91.6\%)..$^{3,6,8,10,14,16}$ Assessment of the perienhancing area with DWI or DTI presents several limitations or challenges. First, primary (de novo) glioblastoma shows minimal microscopic tumor infiltration in the perienhancing area. Therefore, a differentiation from brain metastasis could be challenging. Second, secondary glioblastoma, anaplastic astrocytoma, and oligodendroglioma generally show definite microscopic tumor infiltration in the perienhancing area, even on conventional MR imaging sequences such as FLAIR. Therefore, the added value of advanced MR imaging is controversial. Third, when it comes to extensive peritumoral edema, microscopic tumor infiltration in the perienhancing area could be overestimated on advanced MR imaging.

Glioma cells tend to produce large amounts of extracellular matrix components. ${ }^{19,20}$ This extracellular matrix serves as a substrate for adhesion and subsequent migration of the tumor cells along the enlarged extracellular space. ${ }^{19}$ These molecules are concentrated and are oriented in the extracellular matrix, which results in high FA. ${ }^{15,59}$ In the current meta-analysis, 3 studies demonstrated that high-grade glioma showed higher FA values in enhancing tumor than brain metastases; in 2 of these studies, the difference was statistically significant, ${ }^{4,15}$ though the difference did not reach statistical significance in the other one. ${ }^{3}$ However, 2 further studies did not show any meaningful differences between the 2 groups. ${ }^{9,14}$ A recent systematic review also revealed no significant changes in the FA of enhancing tumor between highgrade glioma and brain metastasis. ${ }^{60}$ The underlying mechanism for this discrepancy is not fully understood, and further studies are required.

Although all the studies using DWI used ADC, the exact parameters varied and included minimum $\mathrm{ADC}$, ADC ratio, gradient of ADC, or a combination of these. Despite the use of these various parameters, DWI is available in most institutions with MR imaging facilities, and the benefit is fast acquisition and easy image processing. ${ }^{11}$ A variety of parameters were also used for DTI, including perienhancing MD and FA of the enhancing tumor. DTI had several drawbacks, including low spatial resolution and image distortion. ${ }^{61}$ Therefore, considerable effort is required to achieve standardization, and further studies are needed.

This study has several limitations. First, only $21.4 \%$ ( 3 of 14) of the included studies were prospective. ${ }^{5,13,16}$ However, the included studies are the only currently available ones. Second, we combined the MR imaging techniques used for diagnostic performance (ie, DWI and DTI). Third, the included studies used various parameters. However, we demonstrated the absence of heterogeneity across the included studies. In addition, we also performed multiple subgroup analyses. Furthermore, we conducted this study using robust methodology (hierarchic logistic regression modeling ${ }^{23}$ ) and have reported the results in accordance with several guidelines (PRISMA, ${ }^{21}$ the Handbook for Diagnostic Test Accuracy Reviews published by the Cochrane Collaboration, ${ }^{62}$ and the Agency for Healthcare Research and Quality $^{63}$ ). Nevertheless, caution is required in applying our results to daily clinical practice.

\section{CONCLUSIONS}

DWI and DTI demonstrated a moderate diagnostic performance for differentiating high-grade glioma from solitary brain metastasis.

\section{REFERENCES}

1. O’Neill BP, Buckner JC, Coffey RJ, et al. Brain metastatic lesions. Mayo Clin Proc 1994;69:1062-68 CrossRef Medline

2. Giese A, Westphal M. Treatment of malignant glioma: a problem beyond the margins of resection. J Cancer Res Clin Oncol 2001;127: 217-25 CrossRef Medline

3. Bauer AH, Erly W, Moser FG, et al. Differentiation of solitary brain metastasis from glioblastoma multiforme: a predictive multiparametric approach using combined MR diffusion and perfusion. $\mathrm{Neu}$ roradiology 2015;57:697-703 CrossRef Medline

4. Bette S, Huber T, Wiestler B, et al. Analysis of fractional anisotropy facilitates differentiation of glioblastoma and brain metastases in a clinical setting. Eur J Radiol 2016;85:2182-87 CrossRef Medline

5. Byrnes TJ, Barrick TR, Bell BA, et al. Diffusion tensor imaging discriminates between glioblastoma and cerebral metastases in vivo. NMR Biomed 2011;24:54-60 CrossRef Medline

6. Caravan I, Ciortea CA, Contis A, et al. Diagnostic value of apparent diffusion coefficient in differentiating between high-grade gliomas and brain metastases. Acta Radiol 2017;59:599-605 CrossRef Medline

7. Chen R, Wang S, Poptani H, et al. A Bayesian diagnostic system to differentiate glioblastomas from solitary brain metastases. Neuroradiol J 2013;26:175-83 CrossRef Medline

8. Han C, Huang S, Guo J, et al. Use of a high b-value for diffusion weighted imaging of peritumoral regions to differentiate highgrade gliomas and solitary metastases. J Magn Reson Imaging 2015; 42:80 - 86 CrossRef Medline

9. Holly KS, Barker BJ, Murcia D, et al. High-grade gliomas exhibit higher peritumoral fractional anisotropy and lower mean diffusivity than intracranial metastases. Front Surg 2017;4:18 CrossRef Medline

10. Lee EJ, terBrugge K, Mikulis D, et al. Diagnostic value of peritumoral minimum apparent diffusion coefficient for differentiation of glioblastoma multiforme from solitary metastatic lesions. AJR Am J Roentgenol 2011;196:71-76 CrossRef Medline

11. Lemercier P, Paz Maya S, Patrie JT, et al. Gradient of apparent diffusion coefficient values in peritumoral edema helps in differentiation of glioblastoma from solitary metastatic lesions. AJR Am J Roentgenol 2014;203:163-69 CrossRef Medline

12. Miquelini LA, Pérez Akly MS, Funes JA, et al. Usefulness of the apparent diffusion coefficient for the evaluation of the white matter to differentiate between glioblastoma and brain metastases. Radiologia 2016;58:207-13 CrossRef Medline

13. Server A, Kulle B, Maehlen J, et al. Quantitative apparent diffusion coefficients in the characterization of brain tumors and associated peritumoral edema. Acta Radiol 2009;50:682-89 CrossRef Medline

14. Tan $\mathrm{Y}$, Wang XC, Zhang $\mathrm{H}$, et al. Differentiation of high-gradeastrocytomas from solitary-brain-metastases: comparing diffusion kurtosis imaging and diffusion tensor imaging. Eur J Radiol 2015; 84:2618-24 CrossRef Medline

15. Wang S, Kim SJ, Poptani H, et al. Diagnostic utility of diffusion tensor imaging in differentiating glioblastomas from brain metastases. AJNR Am J Neuroradiol 2014;35:928-34 CrossRef Medline

16. Zhao J, Yang ZY, Luo BN, et al. Quantitative evaluation of diffusion and dynamic contrast-enhanced MR in tumor parenchyma and peritumoral area for distinction of brain tumors. PLoS One 2015;10: e0138573 CrossRef Medline

17. Watanabe M, Tanaka R, Takeda N. Magnetic resonance imaging and histopathology of cerebral gliomas. Neuroradiology 1992;34:463-69 CrossRef Medline

18. Strugar J, Rothbart D, Harrington W, et al. Vascular permeability factor in brain metastases: correlation with vasogenic brain edema 
and tumor angiogenesis. J Neurosurg 1994;81:560-66 CrossRef Medline

19. Zamecnik J. The extracellular space and matrix of gliomas. Acta Neuropathol 2005;110:435-42 CrossRef Medline

20. Vargová L, Homola A, Zámecník J, et al. Diffusion parameters of the extracellular space in human gliomas. Glia 2003;42:77-88 CrossRef Medline

21. Liberati A, Altman DG, Tetzlaff J, et al. The PRISMA statement for reporting systematic reviews and meta-analyses of studies that evaluate health care interventions: explanation and elaboration. Ann Intern Med 2009;151:W65-94 Medline

22. Whiting PF, Rutjes AW, Westwood ME, et a; QUADAS-2 Group. QUADAS-2: a revised tool for the quality assessment of diagnostic accuracy studies. Ann Intern Med 2011;155:529-36 CrossRef Medline

23. Suh $\mathrm{CH}$, Park SH. Successful publication of systematic review and meta-analysis of studies evaluating diagnostic test accuracy. Korean J Radiol 2016;17:5-6 CrossRef Medline

24. Kim KW, Lee J, Choi SH, et al. Systematic review and meta-analysis of studies evaluating diagnostic test accuracy: a practical review for clinical researchers, Part I: general guidance and tips. Korean J Radiol 2015;16:1175-87 CrossRef Medline

25. Lee J, Kim KW, Choi SH, et al. Systematic review and meta-analysis of studies evaluating diagnostic test accuracy: a practical review for clinical researchers, Part II: statistical methods of meta-analysis. Korean J Radiol 2015;16:1188-96 CrossRef Medline

26. Deeks JJ, Macaskill P, Irwig L. The performance of tests of publication bias and other sample size effects in systematic reviews of diagnostic test accuracy was assessed. J Clin Epidemiol 2005;58:882-93 CrossRef Medline

27. Higgins J, Green S, eds. Cochrane Handbook for Systematic Reviews of Interventions. Version 5.1.0 [updated March 2011]. The Cochrane Collaboration, 2011. Available from http://handbook.cochrane.org. Accessed October 2, 2017

28. Devillé WL, Buntinx F, Bouter LM, et al. Conducting systematic reviews of diagnostic studies: didactic guidelines. BMC Med Res Methodol 2002;2:9 CrossRef Medline

29. Calli C, Kitis O, Yunten N, et al. Perfusion and diffusion MR imaging in enhancing malignant cerebral tumors. Eur J Radiol 2006;58:394403 CrossRef Medline

30. Chiang IC, Kuo YT, Lu CY, et al. Distinction between high-grade gliomas and solitary metastases using peritumoral 3-T magnetic resonance spectroscopy, diffusion, and perfusion imagings. Neuroradiology 2004;46:619-27 Medline

31. Darwiesh AM, Maboud NM, Khalil AM, et al. Role of magnetic resonance spectroscopy \& diffusion weighted imaging in differentiation of supratentorial brain tumors. Egyptian Journal of Radiology and Nuclear Medicine 2016;47:1037-42 CrossRef

32. Guzman R, Altrichter S, El-Koussy M, et al. Contribution of the apparent diffusion coefficient in perilesional edema for the assessment of brain tumors. J Neuroradiol 2008;35:224-29 CrossRef Medline

33. Kitis $\mathrm{O}$, Altay $\mathrm{H}$, Calli $\mathrm{C}$, et al. Minimum apparent diffusion coefficients in the evaluation of brain tumors. Eur J Radiol 2005;55:393400 CrossRef Medline

34. Lu S, Ahn D, Johnson G, et al. Diffusion-tensor MR imaging of intracranial neoplasia and associated peritumoral edema: introduction of the tumor infiltration index. Radiology 2004;232:221-28 CrossRef Medline

35. Papageorgiou TS, Chourmouzi D, Drevelengas A, et al. Diffusion tensor imaging in brain tumors: a study on gliomas and metastases. Phys Med 2015;31:767-73 CrossRef Medline

36. Pavlisa G, Rados M, Pavlisa G, et al. The differences of water diffusion between brain tissue infiltrated by tumor and peritumoral vasogenic edema. Clin Imaging 2009;33:96-101 CrossRef Medline

37. Shim WH, Kim HS, Choi CG, et al. Comparison of apparent diffusion coefficient and intravoxel incoherent motion for differentiating among glioblastoma, metastasis, and lymphoma focusing on diffusion-related parameter. PLoS One 2015;10:e0134761 CrossRef Medline

38. Svolos P, Tsolaki E, Kapsalaki E, et al. Investigating brain tumor differentiation with diffusion and perfusion metrics at 3T MRI using pattern recognition techniques. Magn Reson Imaging 2013;31: 1567-77 CrossRef Medline

39. Tsougos I, Svolos P, Kousi E, et al. Differentiation of glioblastoma multiforme from metastatic brain tumor using proton magnetic resonance spectroscopy, diffusion and perfusion metrics at $3 \mathrm{~T}$. Cancer Imaging 2012;12:423-36 CrossRef Medline

40. Wang W, Steward CE, Desmond PM. Diffusion tensor imaging in glioblastoma multiforme and brain metastases: the role of $p, q, L$, and fractional anisotropy. AJNR Am J Neuroradiol 2009;30:203-08 CrossRef Medline

41. Bobek-Billewicz B, Stasik-Pres G, Majchrzak K, et al. Fibre integrity and diffusivity of the pyramidal tract and motor cortex within and adjacent to brain tumour in patients with or without neurological deficits. Folia Neuropathol 2011;49:262-70 Medline

42. Bulakbasi N, Guvenc I, Onguru O, et al. The added value of the apparent diffusion coefficient calculation to magnetic resonance imaging in the differentiation and grading of malignant brain tumors. J Comput Assist Tomogr 2004;28:735-46 CrossRef Medline

43. Bulakbasi N, Kocaoglu M, Ors F, et al. Combination of single-voxe proton MR spectroscopy and apparent diffusion coefficient calculation in the evaluation of common brain tumors. AJNR Am J Neuroradiol 2003;24:225-33 Medline

44. Cho NS, Jenabi M, Arevalo-Perez J, et al. Diffusion tensor imaging shows corpus callosum differences between high-grade gliomas and metastases. J Neuroimaging 2018;28:199-205 CrossRef Medline

45. Jones TL, Byrnes TJ, Yang G, et al. Brain tumor classification using the diffusion tensor image segmentation (D-SEG) technique. Neuro Oncol 2015;17:466-76 CrossRef Medline

46. Kolakshyapati M, Adhikari RB, Karlowee V, et al. Nonenhancing peritumoral hyperintense lesion on diffusion-weighted imaging in glioblastoma: a novel diagnostic and specific prognostic indicator. J Neurosurg 2018;128:667-78 CrossRef Medline

47. Zolal A, Hejcl A, Malucelli A, et al. Distant white-matter diffusion changes caused by tumor growth. J Neuroradiol 2013;40:71-80 CrossRef Medline

48. Lu S, Ahn D, Johnson G, et al. Peritumoral diffusion tensor imaging of high-grade gliomas and metastatic brain tumors. AJNR Am J Neuroradiol 2003;24:937-41 Medline

49. Wang S, Kim S, Chawla S, et al. Differentiation between glioblas tomas, solitary brain metastases, and primary cerebral lymphomas using diffusion tensor and dynamic susceptibility contrastenhanced MR imaging. AJNR Am J Neuroradiol 2011;32:507-14 CrossRef Medline

50. Wang S, Kim S, Chawla S, et al. Differentiation between glioblas tomas and solitary brain metastases using diffusion tensor imaging. Neuroimage 2009;44:653-60 CrossRef Medline

51. Yang G, Jones TL, Barrick TR, et al. Discrimination between glioblastoma multiforme and solitary metastasis using morphological features derived from the $\mathrm{p}$ : $\mathrm{q}$ tensor decomposition of diffusion tensor imaging. NMR Biomed 2014;27:1103-11 CrossRef Medline

52. Yang G, Jones TL, Howe FA, et al. Morphometric model for discrimination between glioblastoma multiforme and solitary metastasis using three-dimensional shape analysis. Magn Reson Med 2016;75: 2505-16 CrossRef Medline

53. Min ZG, Niu C, Rana N, et al. Differentiation of pure vasogenic edema and tumor-infiltrated edema in patients with peritumoral edema by analyzing the relationship of axial and radial diffusivities on 3.0T MRI. Clin Neurol Neurosurg 2013;115:1366-70 CrossRef Medline

54. Oh J, Cha S, Aiken AH, et al. Quantitative apparent diffusion coefficients and $\mathrm{T} 2$ relaxation times in characterizing contrast enhancing brain tumors and regions of peritumoral edema. J Magn Reson Imaging 2005;21:701-08 CrossRef Medline

55. van Westen D, Latt J, Englund E, et al. Tumor extension in high-grade 
gliomas assessed with diffusion magnetic resonance imaging: values and lesion-to-brain ratios of apparent diffusion coefficient and fractional anisotropy. Acta Radiol 2006;47:311-19 CrossRef Medline

56. Vandendries C, Ducreux D, Lacroix C, et al. Statistical analysis of multi-b factor diffusion weighted images can help distinguish between vasogenic and tumor-infiltrated edema. J Magn Reson Imaging 2014;40:622-29 CrossRef Medline

57. Hoefnagels FW, De Witt Hamer P, Sanz-Arigita E, et al. Differentiation of edema and glioma infiltration: proposal of a DTI-based probability map. J Neurooncol 2014;120:187-98 CrossRef Medline

58. Rollin N, Guyotat J, Streichenberger N, et al. Clinical relevance of diffusion and perfusion magnetic resonance imaging in assessing intra-axial brain tumors. Neuroradiology 2006;48:150-59 CrossRef Medline

59. Pope WB, Mirsadraei L, Lai A, et al. Differential gene expression in glioblastoma defined by ADC histogram analysis: relationship to extracellular matrix molecules and survival. AJNR AmJ Neuroradiol 2012;33:1059-64 CrossRef Medline

60. Jiang $\mathrm{R}, \mathrm{Du} \mathrm{FZ}, \mathrm{He} \mathrm{C}$, et al. The value of diffusion tensor imaging in differentiating high-grade gliomas from brain metastases: a systematic review and meta-analysis. PLoS One 2014;9:e112550 CrossRef Medline

61. Mori S, Zhang J. Principles of diffusion tensor imaging and its applications to basic neuroscience research. Neuron 2006;51:527-39 CrossRef Medline

62. Deeks JJ, Bossuyt PM, Gatsonis C, eds. Cochrane Handbook for Systematic Reviews of Diagnostic Test Accuracy. Version 1.0.0. The Cochrane Collaboration, 2013. http://methods.cochrane.org/sdt/ handbook-dta-reviews. Accessed October 9, 2017

63. Trikalinos TA, Balion CM, Coleman CI, et al. Chapter 8: meta-analysis of test performance when there is a "gold standard." J Gen Intern Med 2012;27(Suppl 1):S56-66 CrossRef Medline 